\title{
Introducing Preservice Teachers to Family-Centered Practices: A Scoping Review
}

\author{
Marcus Daczewitz ${ }^{1}$, Hedda Meadan², Terri Cooper Swanson ${ }^{1}$, Michelle Sands ${ }^{2}$ \\ ${ }^{1}$ Pittsburg State University, United States \\ ${ }^{2}$ University of Illinois, United States \\ Correspondence: Marcus Daczewitz, Pittsburg State University, United States.
}

Received: Sep. 7, $2020 \quad$ Accepted: Sep. 26, $2020 \quad$ Online Published: Oct. 14, 2020

doi:10.11114/jets.v8i11.5003 URL: https://doi.org/10.11114/jets.v8i11.5003

\begin{abstract}
Parental involvement in P-12 education could lead to social and academic success for students; however, parents often experience barriers to their involvement. Different or additional barriers exist for parents of children with a disability. School staff can positively influence parents to become involved in their children's education. Family-centered practices, common in early intervention under special education law (Part C of IDEIA), may foster parent involvement in P-12 schools. In this scoping literature review, we examined 17 studies of teacher preparation programs (TPPs) in higher education in the US who have implemented programs to prepare preservice teachers (PSTs) to collaborate with parents/families. Studies varied by analytic method, participants, purposes, format, and measures. We present a synthesis of the included articles and discuss recommendations for teacher preparation programs.
\end{abstract}

Keywords: family-centered practices, preservice teacher preparation, parent involvement

\section{Introduction}

\subsection{Parental Involvement}

Parental involvement in PreK-12 education can lead to social and academic success for both elementary and secondary students (Jeynes, 2017; Thelamour \& Jacobs, 2014). Parental involvement has been defined as "the resources that parents invest in a child's learning experience" (Calzada et al., 2015, p. 872). Examples may include attending parent-teacher conferences or helping during school events. For the purpose of this review, parent-involvement is defined as activities parents engage in as part of their children's education, either by their own initiation or at the request of school personnel. Throughout this review we will discuss parents and families of children with and without disabilities, as all parents and families stand to benefit from well-trained educators.

The Individuals with Disabilities Education Improvement Act (IDEIA, 2004) requires that parents of children with disabilities be included in the educational decision-making process. Schools meet the requirements of IDEIA by obtaining parental consent for evaluation and programmatic changes, informing parents of progress toward individualized education program (IEP) goals at least as often as typically developing students receive report cards, and inviting parents to attend and participate in IEP meetings. Therefore, while all parents are invited to family nights, back-to-school activities, and parent-teacher conferences, and are typically encouraged to play a role in students' homework completion, parents of children with disabilities have more formal opportunities for educational decision making (IDEIA, 2004).

\subsection{Barriers to Parental Involvement}

Parents often report they experience barriers to becoming involved in their children's education. Barriers include practical issues like economic needs (e.g., lack of adequate transportation or childcare; Pemberton \& Miller, 2015) and scheduling difficulties (Cavendish \& Connor, 2018). However, parents also perceive barriers such as parents' distrust of schools (Pemberton \& Miller, 2015), schools' treatment of race (Lechuga-Peña \& Brisson, 2018; Parsons et al., 2018) and language differences (Cavendish \& Connor, 2018). Cavendish and Connor interviewed a parent whose native language was not English and who reported that "because of my limitations in terms of language they don't take me into account" (p. 38). Allen and White-Smith (2018) found that racial barriers can also hinder parental involvement when parents feel ignored by office staff, teachers, and parent networks because of their race. Parents who feel ignored may 
not feel motivated to become involved in their children's education. In their study, Allen and White-Smith found that when parents of color volunteered to help in the classroom or asked if they could observe, teachers appeared to be intimidated by their presence.

Parental involvement can take on different dimensions and pose different barriers when the parent has a child with a disability. Parents of children with disabilities may perceive societal judgment and feel as though they are being outcast (Valle, 2018). Additionally, the decision-making processes in PreK-12 education can be daunting for parents of children with disabilities. Parents need to advocate for the services their children need but may feel that asking for too much or too often will make them "pushy parents" (Beauvais, 2017; Bibby et al., 2017). Haley, Allsopp, and Hoppey (2018) found that even when a parent was a teacher at their child's school, there were barriers to their inclusion as full team members in their child's educational decision-making team. This parent cited a "learning curve to special education" ( $p$. 26) along with loyalty and job security issues if she complained or did not do what the school thought was right. Curle et al. (2017) interviewed 12 parents of children who were deaf/hard of hearing after their transition to kindergarten. In this study, some parents "voiced a reluctance to disagree with the school team, fearing damage of the relationship between themselves or their child and the teacher" (p. 59).

School staff often recognize the need for parental involvement, but they may not understand the barriers that parents face or may not see the barriers as legitimate reasons for what they perceive to be low parent involvement. Pemberton and Miller (2015) found that "teachers acknowledged the difficulties associated with a worsening economy, but they did not view such challenges as insurmountable obstacles for parents" (p. 750). Helping teachers understand the challenges of family life may help teachers understand and partner with families.

\subsection{The Benefit of School-Family Partnerships}

School staff can positively influence parents to become involved in their children's education. Curry, Gaëtane, and Adams (2016) surveyed a total of 680 parents from among 56 elementary schools and found that school outreach efforts (e.g., invitations from the school), and parents' social networks (i.e., the number of other parents that participants listed as frequent contacts) accounted for $10 \%$ of variance in parents' motivation to become involved at school. This was based on parents' self-reported motivation to become involved and did not measure actual involvement. Jeynes (2007) found that school outreach programs (e.g., invitation sent home with child) had an effect size of 0.29 on parents' self-reported motivation to become involved, indicating that whether involvement is suggested by the school or initiated by parents, there is a positive impact. Similarly, Li and Fischer (2017) found that parent involvement seems to have an iterative effect, leading to networks among parents, which, in turn, foster more parental involvement and school success.

The National Parent-Teacher Association (NPTA; www.pta.org, n.d.) published standards for fostering family-school partnerships. These standards are (a) welcoming all families into the school, (b) communicating effectively, (c) supporting student success, (d) speaking up for every child, (e) sharing power, and (f) collaborating with community. According to the NPTA report, State Laws on Family Engagement in Education (Belway et al., 2010), 40 states have passed legislation requiring professional development to foster family engagement.

\subsection{Family-Centered Practices to Foster School-Family Partnerships}

Early intervention for children birth through 2 (i.e., Part C of IDEIA) has included family-centered services since its inception in 1986. Parents are consulted regarding service delivery decisions, and services are delivered around parent schedules. What is more remarkable is that in early intervention, service providers are expected to treat parents as equal partners with expertise in their children's specific needs and abilities (Division for Early Childhood, DEC, 2014). The DEC has published recommendations for early intervention and early childhood practitioners (2014). Among recommendations for family-centered practices are "build trusting and respectful partnerships with the family through interactions that are sensitive and responsive to cultural, linguistic, and socioeconomic diversity; provide the family with up-to-date, comprehensive, and unbiased information in a way that the family can understand; [be] responsive to family concerns, priorities, and changing life circumstances" (p. 10). In the transition from Part C to Part B, parents are consulted less, and the school takes on the role of expert educator (DEC, 2014; Dunst, 2002).

Parental involvement and family-centered practices are not interchangeable terms. Family-centered practices are a set of beliefs and strategies that are guided by the belief that parents are equal partners in educating children, and yet unknown is the extent to which teachers in public schools have adopted a family-centered approach (Dunst, 2002). Teachers with a family-centered approach would share assessment data freely and consult parents regularly with progress updates and to make decisions on future programming (Bruder, 2010). The assumption is that using family-centered practices will lead to increased parental involvement and that teachers who have been trained in family-centered practices will better establish family-school partnerships and include parents in children's education. However, family-centered practices may not be the norm in public PreK-12 schools (Allen \& White-Smith, 2018; Cavendish \& Connor, 2018; Haley et al., 
2018; Lechuga-Peña \& Brisson, 2018; Pemberton \& Miller, 2015; Valle, 2018).

While the use of family-centered practices may not be the norm within public school settings (Dunst, 2002), groups of people collaborate more effectively when they see each other as equals and find intergroup similarities. Cavendish and Connor (2018) described parent and family realities as "starkly different from those of the school personnel with whom they interact" (p. 81). If school staff seek to positively impact parent-involvement, they may need help understanding the realities that families face. Introducing teachers to family-centered practices early in their career may help them consider family perspectives.

Recently revised standards for elementary teacher preparation programs include statements such as "Candidates work collaboratively with families to gain a holistic perspective on children's strengths and needs and how to motivate their learning" (Council for the Accreditation of Educator Preparation [CAEP], 2018) and "Candidates work respectfully and reciprocally with families to gain insight into each child" (p. 7). Teacher preparation programs provide foundational educational experiences for preservice teachers. These experiences often simulate the work that preservice teachers (PSTs) will perform as teachers. The theory underlying this practice is that PSTs will perform better in their careers if they are provided opportunities to practice within their teacher preparation program (Holdaway \& Owens, 2015; Stoddard et al., 2011). Given that parent involvement is important for student and family outcomes and that partnering with families and using family-centered practices could promote parent involvement, the purpose of this literature review is to examine practices for preparing PSTs to collaborate with families. Because family-centered practices are beneficial for all families, we included studies that targeted PSTs preparing for all $\mathrm{K}-12$ settings.

The following questions guided our review of the literature:

1. What strategies are teacher preparation programs (TPPs) employing to introduce preservice teachers (PSTs) to family-centered practices?

2. How do TPPs' efforts impact PSTs' knowledge, practices, and attitudes toward and efficacy in implementing family-centered practices?

\section{Method}

\subsection{Literature Search}

The purpose of this study was to identify and review existing research on the strategies for preparing teachers to implement family-centered practices in PreK-12 settings. Studies were identified by searching electronic databases including Academic Search Premier (1975-Present) and Psycinfo (1877-Present). The last search occurred on January $29,2020$.

We used the following search terms to search the databases: family-centered, teacher, education, family, preparation programs, preservice teachers, and parent. Studies were screened for inclusion by the first author based on a review of titles that mentioned teacher preparation programs, preservice teachers, and family-centered practices or family-focus. Titles and abstracts that on first review met inclusion criteria were set aside for further review.

After a thorough search for articles that seemed to fit our criteria, we eliminated articles that did not fit all inclusion criteria: (a) peer-reviewed article; (b) written in English; (c) involved preservice K-12 teachers; (d) published between 2007 and 2018; (e) include an empirical study; and (f) sought to improve the attitudes, knowledge, and/or skills for working with parents/families of future students. We conducted an abstract review, removing duplicate articles and those that did not meet all inclusion criteria. We then conducted forward and backward ancestral searches using the remaining articles and reviewed the abstracts for items found in these searches. Finally, we conducted a full-text review to ensure that the remaining studies met our criteria.

\subsection{Creation of Data Extraction Protocol}

To standardize data extraction, we developed a data collection form, pilot tested it with two randomly selected remaining articles, and made changes based on these results. The first and fourth authors extracted the data using the data collection form and compared their findings. Disagreements were resolved through discussion and clarifying any misleading instructions in the data collection form. The following data items were sought in each article: (a) methodology, (b) study purpose, (c) description of participants, (d) description of intervention, (e) measures of outcomes, and (f) key findings. 


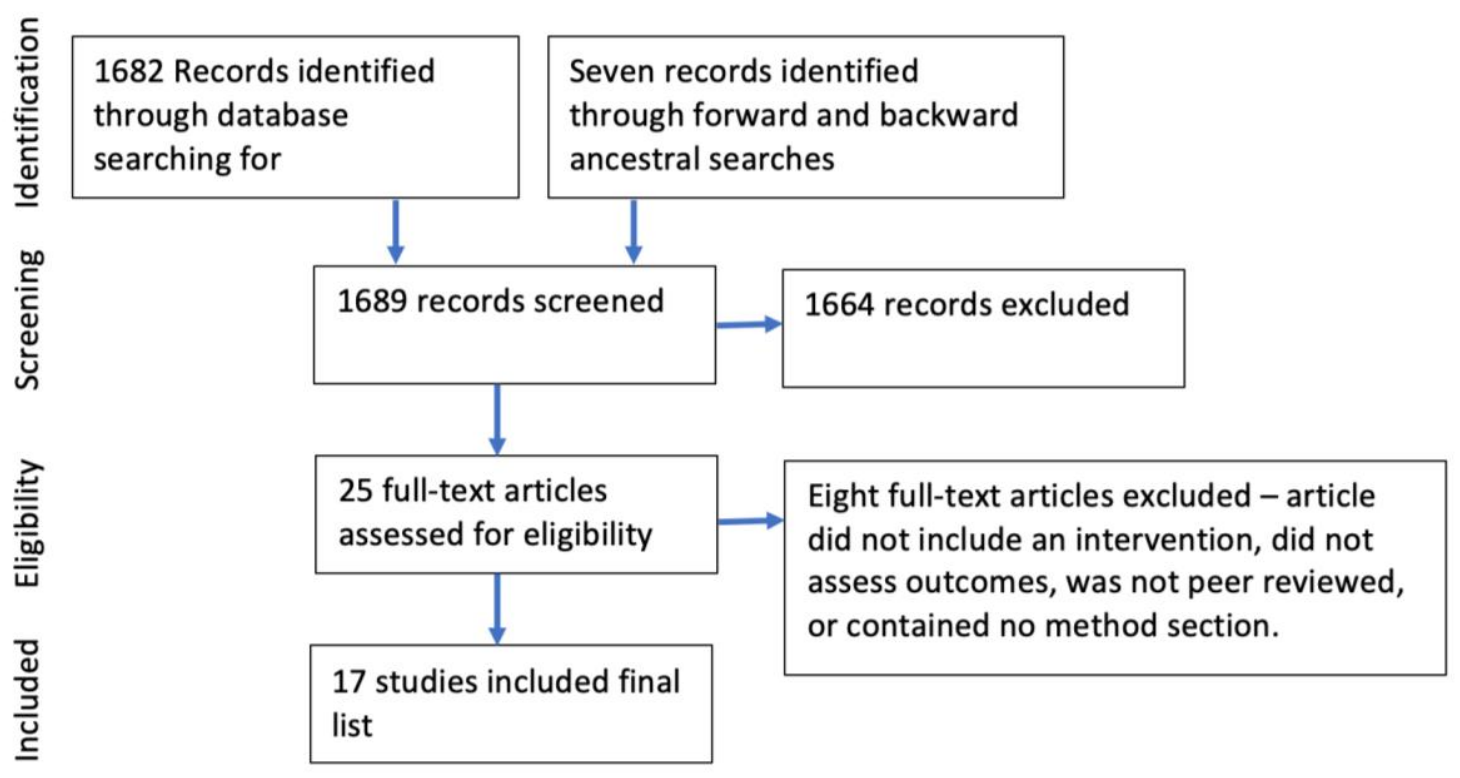

Figure 1. Flow Diagram of Study Selection

\subsection{Data Extraction}

With the data extraction protocol created, the first and fourth authors separately extracted the data from the included articles. They met to compare their protocols and reached agreement on what was to be included in the final data table. Some disagreements occurred in (a) participant information, typically regarding math errors and pulling accurate numbers from the article; and (b) description of the intervention, where it was difficult to find specific information in the article. To resolve these, we referred back to the articles together and found the relevant information.

\section{Results}

\subsection{Study Selection}

The search in Academic Search Premier and Psycinfo yielded a total of 1,682 citations. An ancestral search yielded seven additional studies (three from a backward search and four from a forward search). Two team members reviewed the abstracts and removed studies when it became clear they did not meet the inclusion criteria. The full texts of the remaining 25 studies were reviewed independently by the two authors and eight were removed because they did not meet inclusion criteria, for a total of 17 articles in the final list of included studies (see Figure 1 for further information regarding the search procedures).

\subsection{Methodology Within Reviewed Studies}

We identified 17 articles in this review. Table 1 contains information about methodology, study purpose and focus, and demographic information about participants. Table 2 contains descriptions of interventions and key findings. Each table is organized beginning with qualitative studies and followed by quantitative and multiple methods studies.

\subsubsection{Study Characteristics}

Of the 17 included articles, eight featured qualitative analysis only (Able et al., 2014; Amaro-Jimenez, 2016; Amatea et al., 2013; Bofferding, Hoffman, \& Kastberg, 2016; Bottoms, Ciechanowski, Jones, de la Hoz, \& Fonseca, 2017; McHatton et al., 2013; Murray et al., 2008; Waddell, 2013; Zeichner, Bowman, Guillen, \& Napolitan, 2016); four featured quantitative analysis only (Accardo \& Xin, 2017; Bingham \& Abernathy, 2007; Brown et al., 2014; Jacobbe et al., 2012), and three featured a combination of quantitative and qualitative methods or described their study as mixed methods (Bergman, 2013; McCullough \& Ramirez, 2012; Ramirez et al., 2016).

\subsubsection{Participants}

The studies included a total of 3,445 participants. The participants were all preservice teacher candidates in either undergraduate or graduate programs leading to a teaching license. Program majors included elementary education, math education, bilingual education, secondary education, special education, early childhood education, dual special and elementary education, and health education. Some studies did not report on majors (Able et al., 2014; Amaro-Jimenez, 2016; Amatea et al., 2013; Bofferding et al., 2016; Brown et al., 2014; Jacobbe et al., 2012; Murray et al., 2008). The majority of participants in all studies reporting on gender were female and Caucasian, but studies also included African American PSTs (Able et al., 2014; Accardo \& Xin, 2017; Amatea et al., 2013; Collier et al., 2015; Jacobbe et al., 2012; 
Waddell, 2013), Latino PSTs (Able et al., 2014; Accardo \& Xin, 2017; Bottoms et al., 2017; Ramirez et al., 2016), Asian-American PSTs (Able et al., 2014; Amatea et al., 2013; Bottoms et al., 2017; Brown et al., 2014; Jacobbe et al., 2012); Pacific Islander PSTs (Amatea et al., 2013; Bottoms et al., 2017), biracial PSTs (Amatea et al., 2013), and those selecting "other" in this category (Brown et al., 2014; Collier et al., 2015). A detailed listing of participants is found in Table 1.

\subsubsection{Study Purpose}

The included studies featured purposes of determining the impact of different activities on PSTs. The studies implemented interventions with goals of preparing PSTs to work with parents. Most studies used the term parent involvement and sought to help PSTs understand parents. While these do not make up the entire philosophy of family-centered practices, they are a portion of them. Eleven studies sought to determine the influence of specific interventions on PSTs' dispositions toward working with families (Able et al., 2014; Amatea et al., 2013; Bergman, 2013; Bingham \& Abernathy, 2007; Bofferding et al., 2016; Bottoms et al., 2017; Brown et al., 2014; Collier et al., 2015; Jacobbe et al., 2012; McHatton et al., 2013; Waddell, 2013). In addition to perspectives, studies also sought to report on experiences (Waddell, 2013), changes in approaches to working with parents (Amatea et al., 2013), and changes in knowledge of "six types of parent involvement" (Brown et al., 2014, p. 141).

Four studies stated goals of examining PST resulting preparedness or ability to work with parents and families: (a) impact on parent-teacher conference facilitation, professional communication, and instructional decisions (Accardo \& Xin, 2017); (b) PST ability to engage families in a culturally responsive way (McCollough \& Ramirez, 2012); (c) impact on PST preparedness with respect to parent/professional partnerships (Murray et al., 2008); and (d) impact on learning and ability to implement community teaching (Zeichner et al., 2016). These studies examined changes in PST attitudes and beliefs. Amaro-Jimenez (2016) sought to understand PSTs' self-reported confidence and subsequent plans for home-school connections and Ramirez et al. (2016) focused on changes in perceptions toward Latino parents.

Table 1. Study Features

\begin{tabular}{|c|c|c|c|}
\hline Study & Methodology & Study Purpose \& Focus & Participants \\
\hline \multicolumn{4}{|l|}{ Qualitative Methods } \\
\hline \multirow[t]{4}{*}{ Able et al., 2014} & \multirow[t]{4}{*}{ Qualitative, focus group data } & Determine influence on "dispositions toward & $N=68$ \\
\hline & & working with families with diverse & Gender: $\mathrm{F}=59, \mathrm{M}=9$ \\
\hline & & $\begin{array}{l}\text { backgrounds and their skills in collaborating } \\
\text { with families" (p. 11). }\end{array}$ & $\begin{array}{c}\text { Ethnicity: } 57 \text { Caucasian, seven African } \\
\text { American, two Latina, two Asian }\end{array}$ \\
\hline & & $\begin{array}{l}\text { Focus on PST knowledge gains regarding } \\
\text { implications of differences among families }\end{array}$ & $\begin{array}{l}\text { Age: } 20-22 \quad(n=29), 23-25 \quad(n=13), \text { and } \\
28-30(n=2) .\end{array}$ \\
\hline $\begin{array}{l}\text { Amaro-Jimenez, } \\
2016\end{array}$ & $\begin{array}{l}\text { Qualitative, student projects, } \\
\text { reflections, assignments }\end{array}$ & $\begin{array}{l}\text { Identify perceived gains and subsequent } \\
\text { plans for home-school connections }\end{array}$ & $\begin{array}{l}N=104 \text {, Demographic information not } \\
\text { reported }\end{array}$ \\
\hline & & Focus on self-reported confidence & \\
\hline \multirow{3}{*}{$\begin{array}{l}\text { Bofferding et al., } \\
2016\end{array}$} & \multirow{3}{*}{$\begin{array}{l}\text { Qualitative, case study and } \\
\text { surveys }\end{array}$} & Examine changes in PST perceptions and & $N=43$ \\
\hline & & attitudes about collaborating with parents & Gender: $\mathrm{F}=41, \mathrm{M}=2$ \\
\hline & & $\begin{array}{l}\text { Focus on PST attitudes about working with } \\
\text { parents and beliefs/perceptions about parents }\end{array}$ & Year: Final semester of UG program \\
\hline
\end{tabular}

Bottoms et al., 2017 Repeated measures, qualitative reflection papers

McHatton et al., Qualitative, reflective writing 2013

Murray

et al., 2008

Repeated measures, qualitative, focus groups

Waddell, 2013

Qualitative, course assignments $\&$ reflections
Determine changes in PSTs' perceptions about working with linguistically diverse children and families

Focus on attitudes toward society and families

Determine change in PST perceptions toward diverse families of children with disabilities Focus on attitudes toward working with families

Explore impact on PST preparedness with respect to parent/professional partnerships Focus on attitudes toward families and working with families

Report on experiences and perspectives of PSTs

Focus on attitude toward working with families

Zeichner et al., Qualitative, focus groups, Evaluate program impact on PST learning
$N=53$ (fall term $n=25$, spring term $n=29$, one fall student repeated in spring)

Gender: $\mathrm{F}=92 \%, \mathrm{M}=8 \%$

Ethnicity: 47 Caucasian, four Latino/a, two Asian-American, one Pacific Islander Year/Major: Jr. or $\mathrm{Sr}$. standing/Elementary Education

$\mathrm{N}=316$

Major: Elementary and Secondary

Education

$N=9$

Gender: $\mathrm{F}=6, \mathrm{M}=3$

Year: Jr. or Sr. standing

$N=24$

Gender: $F=20, M=4$

Ethnicity: 14 Caucasian, 10 African American

Year/Major: Sr. Sear/Elementary education

$N=129$ 
2016

interviews, observations, document reviews, and surveys
Quantitative/Mixed Methods

Accardo \& Xin, Quasi-experimental quantitative, 2017 treatment + control postintervention surveys

$\begin{array}{ll}\begin{array}{l}\text { Amatea } \\ \text { et al., 2013 }\end{array} & \begin{array}{l}\text { Repeated measures quantitative } \\ \text { questionnaire Qualitative, } \\ \text { problem-solving task }\end{array} \\ \text { Bergman, 2013 } & \begin{array}{l}\text { Repeated measures } \\ \text { mixed-methods survey }\end{array}\end{array}$

Bingham \& Quantitative, Abernathy, $2007 \quad$ concept maps

PST-created
Investigate impact on parent-teacher conference facilitation, professional communication, and instructional decisions Focus on PST attitudes and beliefs toward working with families

Investigate changes in attitudes and approaches toward working with families Focus on PST attitudes toward working with families

Explore changes in perceptions of family engagement

Focus on PST knowledge of practices for inviting parent involvement

Determine changes in attitudes toward working with students' families

Focus on PST attitudes toward working with families

\section{Brown \\ et al., 2014 \\ Quantitative, quasi-experimental}

Collier

et al., 2015

Qualitative and quantitative, questionnaire

Jacobbe et al., 2012
Repeated measures, quantitative survey
McCollough \&
Ramirez, 2012 $\quad \begin{aligned} & \text { Repeated measures mixed } \\ & \text { methods }\end{aligned}$

Ramirez et al., Mixed methods, repeated 2016 measures questionnaire, postevent reflection and ability to implement community teaching Focus on attitudes toward working with families
Evaluate impact on teacher candidates' knowledge and attitude toward parent involvement

Focus on knowledge of " 6 types of parent involvement" and attitudes toward working with families

Examine impact on PST dispositions toward home-school collaboration

Focus on PST attitudes toward working with families

Examine impact on PST perceptions of low-income parents and their engagement in children's education

Focus on perceptions of families
All participants were surveyed during and at the end of their program

Interviews $(n=12)$, Focus groups $(n=16)$, First year teaching interviews $(n=7)$

Year/Major: Graduate/65 Elementary, 64 Secondary

$\mathrm{N}=62(\mathrm{TG}=38 ; \mathrm{CG}=24)$

Gender: $\mathrm{F}=53 \%, \mathrm{M}=47 \%$

Ethnicity: 59 Caucasian, 1 African American, 2 Hispanic

Year/Major: Jr. Standing/TG-5 Elementary Majors, 33 Secondary Majors; CG-24 Secondary Majors

$N=138$

Ethnicity: 105 Caucasian, 10 African American, 12 Latino, eight Asian/Pacific Islander, one biracial

$N=100$, Suburban $(n=60)$, Urban $(n=40)$

Gender: Suburban $\mathrm{F}=48 \%, \quad \mathrm{M}=52 \%$;

Urban $\mathrm{F}=66 \%, \mathrm{M}=34 \%$

Ethnicity: $95 \%$ white

Year: Jr. standing

Major: Secondary education

$N=49$; 24 in first semester, 25 in second semester

Gender: $F=44, M=5$

Ethnicity: NR

Year: $36 \mathrm{UG}, 13 \mathrm{Grad}$

Majors: UG-six special education, one early childhood, 29 dual major elementary and special education

G-12 Special Education, one Health/PE Major

$N=1658$ students from four university teacher-preparation programs

Gender: $\mathrm{F}=84.9 \%, \mathrm{M}=15.1 \%$

Ethnicity: $\quad 62.3 \%$ Caucasian, $6.3 \%$

African American, $0.3 \%$ Asian American, $2.1 \%$ "other"

Year: UG=92.5\%, G=7.5\%

$N=28$

Ethnicity: 17 Caucasian, 5 Hispanic, 3

African American, 3 "other"

Urban placed=22, Rural placed $=6$

Year/Major: Graduate level/Special Education

$N=67(\mathrm{TG}=24, \mathrm{CG}=43)$

Gender: $\mathrm{F}=64, \mathrm{M}=3$

Ethnicity: TG=20 Caucasian, three Hispanic, one Asian; $\mathrm{CG}=36$ Caucasian, four Hispanic, two African American, one Asian

Age/Year: Median age 21, Undergraduate math methods course

$N=502$

Major: Elementary Education

culturally responsive way

Focus on PST attitudes and perceptions of families at the event

Understand impact on PSTs and Latino parent participants Focus on perceptions toward Latino parents

$N=95$ Latino PSTs at two universities Course: 51 math education, 44 bilingual education

\section{$\mathrm{UG}=$ Undergrad, $\mathrm{G}=\mathrm{Grad}$, ELTEP=Elementary education, $\mathrm{STEP}=$ Secondary education}

\subsubsection{Intervention Format}

Of the studies included, six took place over an entire semester through course participation (Amaro-Jimenez, 2014; Bingham \& Abernathy, 2007; Brown et al., 2014; Collier et al., 2015; Murray et al., 2008; Waddell, 2013). Two studies 
incorporated field or practicum hours (Able et al., 2014; Waddell, 2013), while five took place at one (Bofferding et al., 2016; Jacobbe et al., 2012; McCollough \& Ramirez, 2012; \& Ramirez et al., 2016) or two (Bottoms et al., 2017) family nights held at the schools with academics-based activities for children along with preparation for these nights.

Direct interaction with parents/families. Murray et al. (2008) invited families to weekly class sessions where they kept up with course readings and participated in group projects with the PSTs. Within the semester-long course, PSTs in Bingham and Abernathy (2007) interviewed family members and parents of children with disabilities to gain insight into family life. Collier et al. (2015) implemented a Families as Faculty (FAF) program in which PSTs were introduced to family members in class and then were required to visit and interview families in their homes. Similarly, PSTs in Able et al. (2014) visited families in their homes to learn about and provide support to the families.

Family activity nights. Five studies provided direct interaction between PSTs and families through family activity nights centered around academic subjects (Bofferding, 2016; Bottoms et al., 2017; Jacobbe et al., 2012; McCollough \& Ramirez, 2012; Ramirez et al., 2016). The family activity nights were activities incorporated into a semester-long course for PSTs but were also the interventions being assessed in the articles.

One-time experiences with no direct interaction with families. Some studies featured a one-time event or class session. McHatton et al. (2013) involved no contact with parents/families and employed a dramatic reading of found poems. Found poems "take existing texts and refashion them, reorder them, and present them as poems" (poets.org, n.d.). McHatton et al. used interviews with parents from a previous study to create their found poems. Accardo and Xin (2017) compared TeachLive ${ }^{\mathrm{TM}}$ mixed reality simulation to traditional role-play simulations in class in groups of PSTs. Groups in both mixed-reality and role-play simulations were required to develop 504 plans for fictitious students.

Semester-long courses. PSTs in nine studies participated in several experiences conducted as part of a semester-long course (Able et al., 2014; Amaro-Jimenez, 2016; Amatea et al., 2012; Bergman, 2013; Bingham \& Abernathy, 2007; Brown et al., 2014; Collier et al., 2015; Murray et al., 2008; Waddell, 2013). Four of the courses required PSTs to complete field observation hours (Able et al., 2014; Amaro-Jimenez, 2016; Bergman, 2013; Waddell, 2013), while three others hosted parents in university classrooms (Bingham \& Abernathy, 2007; Collier et al., 2015; Murray et al. 2008), and the remaining two studies used simulation, lectures, videos, and readings (Amatea et al., 2012; Brown et al., 2014).

Program-wide intervention. Zeichner et al. (2016) featured a 2-year graduate program with a "Community Teaching Strand" in which panels made up of community elders and family members presented on various topics of interest to PSTs as future teachers and community members.

Technology-based interventions. Brown et al. (2014) used a web-based curriculum to deliver their content and supplemented the web-based component with instructor lecture and discussions. This implementation varied by university participating in the study. Accardo and Xin (2017) employed TeachLive ${ }^{\mathrm{TM}}$ to simulate conference facilitation, professional communication, and instructional decision-making.

\subsubsection{Study Measures}

For studies including quantitative methodology, we noted whether the instrument was standardized, developed by the researchers, or if the researchers used a combination of both. One study employed a standardized measure (McCollough \& Ramirez, 2012); five studies employed a measure created specifically for the study (Accardo \& Xin, 2017; Bergman, 2013; Bingham \& Abernathy, 2007; Collier et al., 2015; Jacobbe et al., 2012); and two studies used both a standardized measure and a researcher-developed measure (Amatea et al., 2013; Brown et al., 2014).

\subsection{Results from Included Studies}

This portion of the results report is divided into qualitative studies and quantitative plus qualitative studies. See Table 2 for a listing of key findings.

\subsubsection{Qualitative Studies}

Eight studies employed qualitative methodology (Able et al., 2014; Amaro-Jimenez, 2016; Bofferding et al., 2016; Bottoms et al., 2017; McHatton et al., 2013; Murray et al., 2008; Waddell, 2013; Zeichner et al., 2016). Each of these studies reported positive outcomes in the findings based on qualitative analysis. Studies in this section reported changes in understandings of families and their differences and needs, attitudes toward parent involvement, and the importance of outreach efforts to include and engage families at school. Specific outcomes are described below and in Table 2.

Increased confidence. PSTs increased their confidence in interacting and working with families as a result of interventions (Amaro-Jimenez, 2016; Bofferding et al., 2016; Murray et al., 2008; Waddell, 2013). In preintervention, several PSTs expressed fear, anxiety, feeling unprepared, lacking experience, or lacking confidence in their ability to work with families. In each of the studies listed above, outcomes included newfound confidence and feelings of preparedness. 
Table 2. Study Activities and Findings

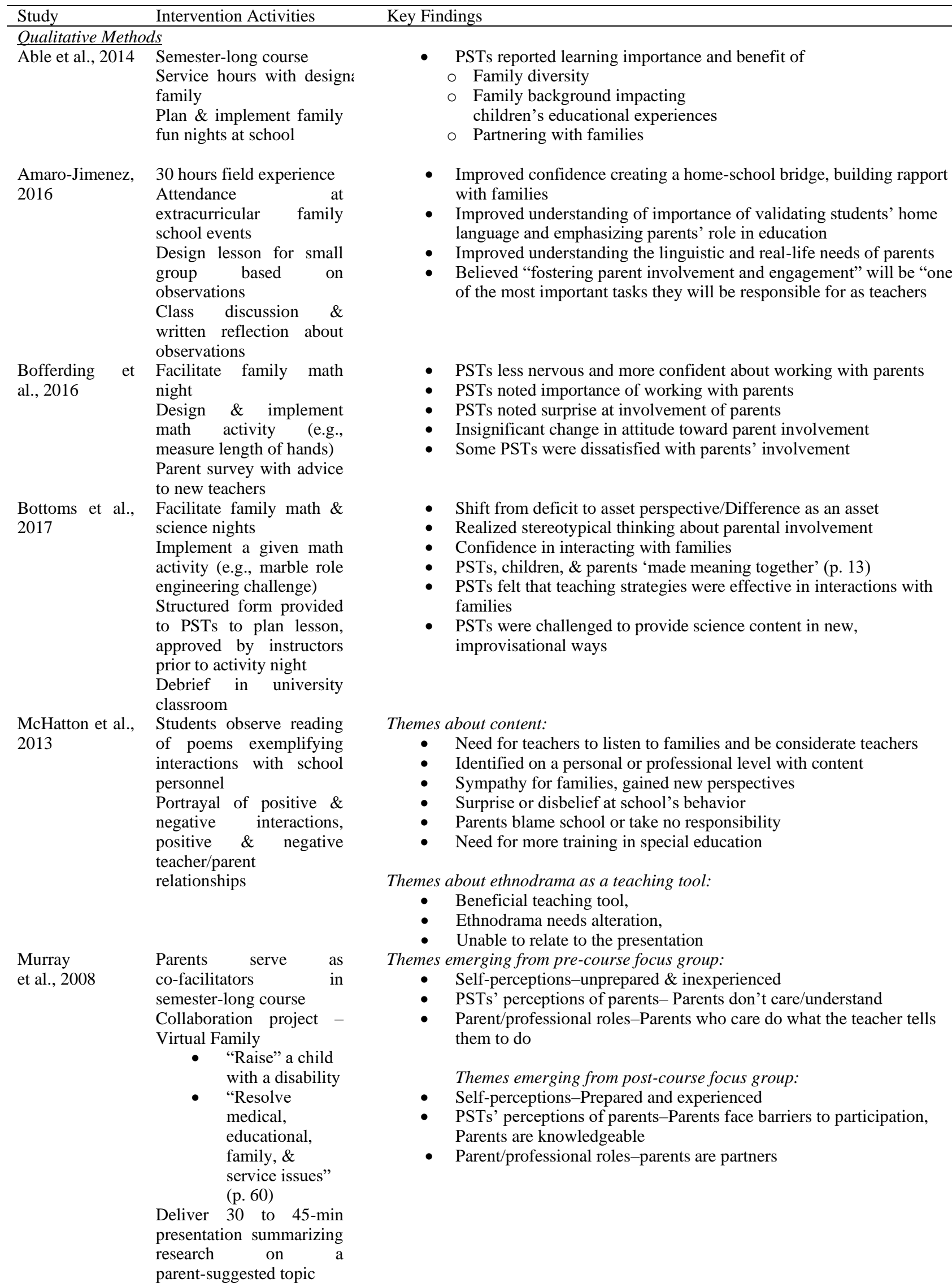


Waddell, 2013 Three panel presentations containing principals, teachers, and parents

Field-based activities guided by instructors:

Neighborhood visits;

Interviewing teachers;

Family survey \&

interview;

Community/family

events; Parent-teacher

conferences; Visits to

family home

Zeichner et al., Panel presentations \& 2016 debriefs on various topics (e.g., hopes and dreams, school-to prison-pipeline)

Small

group

conversations of concerns about working with parents

One-credit field-seminar

course: Studies in

Cultural Awareness
Themes:

- Fear and anxiety about working with families

- Importance of working with families

- Awareness of ineffective current school practices (e.g., negative assumptions about families)

- Awareness of teacher's responsibility for creating authentic relationships with families

- Commitment to establishing collaborative family-school relationships

\section{Teacher Candidate Learning}

- Re-positioning families from barriers to resources

- Translating knowledge to action taken in the classroom

- The first year of teaching

Programmatic Features

- Spaces for curricular integration

- All panels provided a space for "emotion in the room"

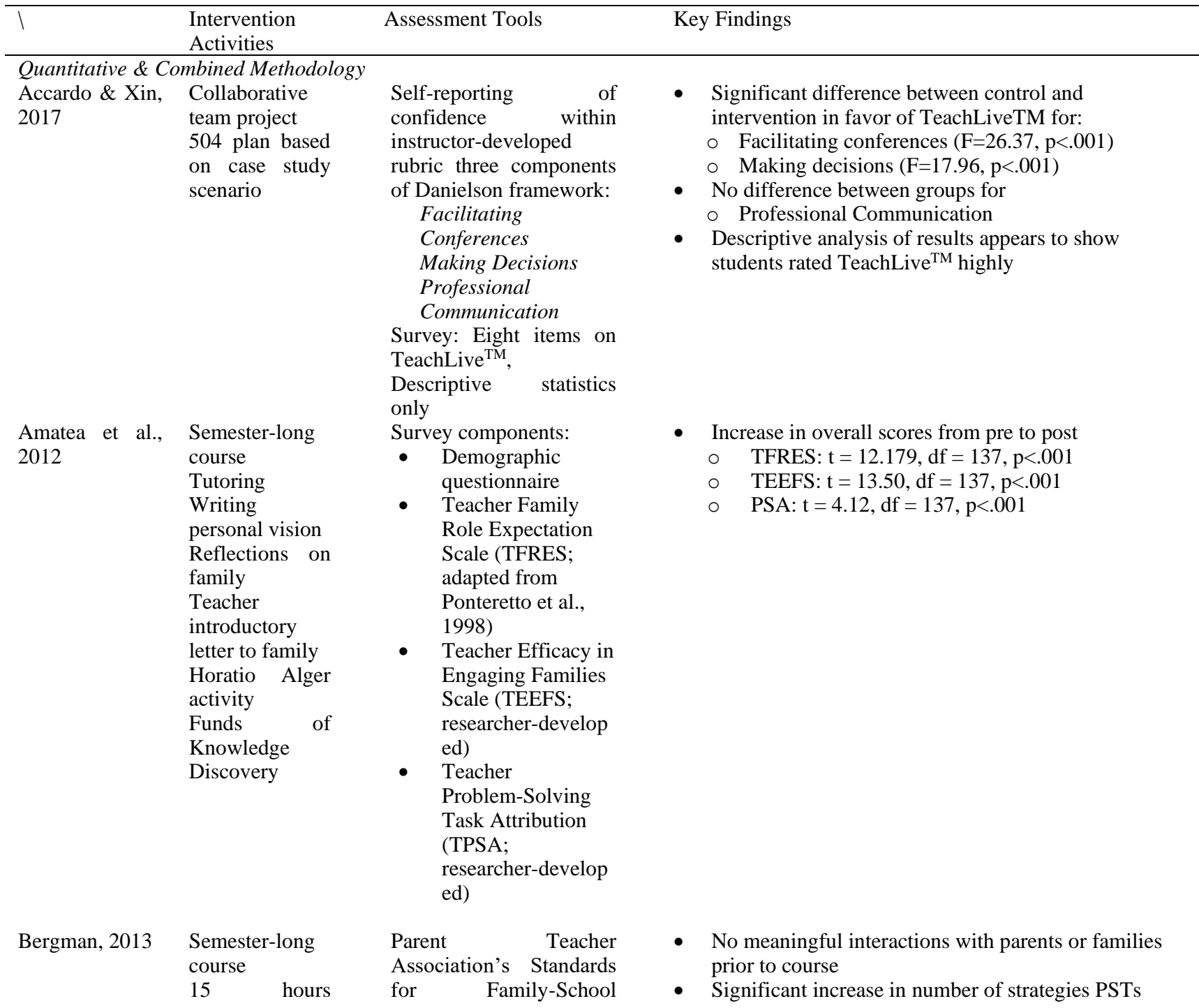




\begin{tabular}{|c|c|c|}
\hline & $\begin{array}{l}\text { classroom } \\
\text { observation } \\
\text { Guest speakers } \\
\text { in class } \\
\text { Book study } \\
\text { examining } \\
\text { resources on } \\
\text { family } \\
\text { engagement } \\
\text { Introductory } \\
\text { letter to } \\
\text { parents/ } \\
\text { guardians }\end{array}$ & $\begin{array}{l}\text { Partnerships } \\
\text { (Researcher-developed, } \\
\text { based on PTA, 2010) }\end{array}$ \\
\hline $\begin{array}{l}\text { Bingham \& } \\
\text { Abernathy, } \\
2007\end{array}$ & $\begin{array}{l}\text { Semester-long } \\
\text { course } \\
\text { Review of } \\
\text { personal beliefs } \\
\text { about families } \\
\text { "Crossing the } \\
\text { Line" activity } \\
\text { Role-playing } \\
\text { poverty } \\
\text { simulation } \\
\text { game } \\
\text { Interview with } \\
\text { own } \\
\text { "caregiver" and } \\
\text { caregiver of a } \\
\text { child with a } \\
\text { disability }\end{array}$ & $\begin{array}{l}\text { Researcher-developed } \\
\text { pre/post concept map } \\
\text { featuring } \\
\text { Positioning of teacher \& } \\
\text { family members as } \\
\text { experts } \\
\text { Service provision priority } \\
\text { is: } \\
\text { Child } \\
\text { Service provision } \\
\text { System } \\
\text { Mix of above } \\
\text { Not evident from } \\
\text { concept map }\end{array}$ \\
\hline $\begin{array}{l}\text { Brown et al., } \\
2014\end{array}$ & $\begin{array}{l}\text { PTE } \\
\text { Curriculum } \\
\text { Modules } \\
\text { Implemented } \\
\text { differently } \\
\text { across } \\
\text { institutions }\end{array}$ & $\begin{array}{l}\text { Researcher-developed } \\
\text { PTE Connect modules } \\
\text { based on framework of } \\
\text { National PTA standards; } \\
\text { Attitude Toward Parent } \\
\text { Involvement survey } \\
\text { (Epstein, } \\
\text { Connors-Tadros, \& } \\
\text { Salinas, 1993) }\end{array}$ \\
\hline $\begin{array}{l}\text { Collier et al., } \\
2015\end{array}$ & $\begin{array}{l}\text { Families as } \\
\text { Faculty (FAF) } \\
\text { Visit to FAF } \\
\text { home } \\
\text { Reflection } \\
\text { paper } \\
\text { Wrap-up } \\
\text { session }\end{array}$ & $\begin{array}{l}\text { Researcher-developed } \\
\text { questionnaire: } \\
\text { Assessment of } \\
\text { self-perceptions of } \\
\text { communication and } \\
\text { listening skills, level of } \\
\text { understanding impact of } \\
\text { disability on family } \\
\text { dynamics, \& capacity to } \\
\text { empathize with parents } \\
\text { and children }\end{array}$ \\
\hline
\end{tabular}

Jacobbe

et al., 2012
Facilitated math activities (e.g., Tangram puzzles) Carnival in school cafeteria Children play academic
Researcher-developed pre/post survey $+1-y r$ follow-up survey Questions pertaining to PST perception of parent involvement with children's education, and use of strategies to help identified for welcoming parents and families following course

- Increase in number of PSTs mentioning "Written Letter" as method of welcoming families

- Urban-placed PSTs shared significantly more welcoming strategies (Wilk's Lambda $=.70$, $F(1,96)=42.10, p<.01)$

- Increases:

○ Communication-"Advocacy for children"

Importance of "Role of parents"

- Understanding of "Family Issues"

- Decreases:

○ Importance of "Role of the school/teachers" decreased

○ Importance of "Improving academic outcomes/Pedagogy" decreased

Overall PST knowledge increased and attitude improved significantly after course

Reflection paper analysis:

- Enhanced understanding of importance of effective communication between families and schools, relationship building, \& positive language used in IEP process

- Enhanced understanding of complexity of families' lives, challenges of home life with a child with a disability, need for school to be cognizant of challenges families face, but no need to pity families

Questionnaire analysis:

- $\quad$ Significant increase in understanding of how experience will influence role as teacher with families

- $\quad$ Significant increase in confidence

3-yr follow-up survey $(n=12)$ :

- All reported FAF was positive for classroom practices.

- $\quad$ Four indicated making efforts to encourage parent participation in IEP process

Pre/post survey

- No differences between CG \& TG on pre survey

- No difference from pre to post survey for CG

- $\quad$ Significant differences on post survey for TG in all but one item ("Parents stress the importance of homework")

1-yr follow-up survey 


$\begin{array}{ll}\text { games } & \text { their children (e.g., } \\ 25 \text { door prizes } & \begin{array}{l}\text { helping with homework, } \\ \text { instilling importance of } \\ \text { awarded } \\ \text { Parents given } \\ \text { homewrce kits }\end{array}\end{array}$

\begin{tabular}{|c|c|c|}
\hline $\begin{array}{l}\text { McCollough \& } \\
\text { Ramirez } 2012\end{array}$ & $\begin{array}{l}\text { Family science } \\
\text { night } \\
\text { Create } \\
\text { culturally } \\
\text { responsive } \\
\text { science } \\
\text { activities }\end{array}$ & $\begin{array}{l}\text { Two subscales of the } \\
\text { SEBEST (Ritter et al., } \\
\text { 2001): Personal science } \\
\text { teaching efficacy \& } \\
\text { Science teaching } \\
\text { outcomes expectancy }\end{array}$ \\
\hline $\begin{array}{l}\text { Ramirez } \\
\text { et al., } 2016\end{array}$ & $\begin{array}{l}\text { Family } \\
\text { Math/Science } \\
\text { Learning Event } \\
\text { Research } \\
\text { history of } \\
\text { culturally } \\
\text { related math or } \\
\text { science topic } \\
\text { Present to } \\
\text { families } \\
\text { Reflection }\end{array}$ & $\begin{array}{l}\text { Researcher-developed } \\
\text { parent involvement } \\
\text { questionnaire }\end{array}$ \\
\hline
\end{tabular}

- One significant difference from pre-survey to follow-up (Parents' willingness to ask for ideas to help at home)

- One significant negative difference from post-survey to follow-up (parents' willingness to attend school activities)

- Five significant differences in positive direction between TG \& CG

Significantly more confident engaging parents in children's education (elementary PSTs $p=.0005$; middle school PSTs $p=.0003)$.
Reflection Themes

PSTs learned:

- $\quad$ how to work with parents,

- about becoming a culturally responsive teacher,

- that Latino parents value education, and

- about barriers for parental involvement

Significant Questionnaire Items

- Many ELLs are not succeeding in school because their parents do not speak English at home (Pre $=44 \%$, Post $=26 \%$ )

- $\quad$ Parents who speak Spanish do not support their children's education (Pre $=5 \%$, Post $=2 \%$ )

PTE=Parent Teacher Education; SEBEST = Self-Efficacy Beliefs about Equitable Science Teaching;

Only results related to family-centered practices and social validity of interventions were included in table.

Perceptions about parents and families. As a result of some interventions, PSTs shifted their perspectives about families in general. For example, PSTs in Bottoms et al. (2017) and Zeichner et al. (2016) shifted from a deficit perspective to an asset perspective when thinking about families. Rather than seeing differences between school and families as something to work around, they now saw this as something that would enhance the experience. These PSTs also addressed their stereotypical thinking about families, as did PSTs in other studies (McHatton et al. 2013; Murray et al. 2008).

For the majority of PSTs, perceptions of parents and families were positive. "It was really cool how many parents were invested in their children's education" (Bofferding, 2016, p. 22). Some perceptions of parents and families were not positive or transformative. A few PSTs at the family night in Bofferding et al. expressed dissatisfaction with parents who remained distant while PSTs worked with the children.

Families as assets. In Waddell (2013) and McHatton et al. (2013), PSTs recognized the need to change the status quo or the established reality in public schools. This suggests they did not understand the importance of positive practice, but they could identify practices that may be counterproductive. In a few studies, researchers found that PSTs became aware that the work they do to welcome and partner with families will be one of the most important parts of their careers (Amaro-Jimenez, 2016; Bofferding et al., 2016; Waddell, 2013).

Social validity. Only one of the identified studies (McHatton et al., 2013) reported on PST perceptions of the process (i.e., the intervention they participated in). This study delivered content through dramatic reading of poems. Some PSTs felt that this was a beneficial tool, while others thought it needed alteration. Some PSTs reported that they were unable to relate to the presentation. These poems were meant to evoke empathy for families. The poems were read by faculty in a university classroom setting and no families were present.

\subsubsection{Quantitative and Combined Method Studies}

Nine studies employed quantitative methodologies (Accardo \& Xin, 2017; Amatea et al., 2013; Bergman, 2013; Bingham \& Abernathy, 2007; Brown et al., 2014; Collier et al., 2015; Jacobbe et al., 2012; McCollough \& Ramirez, 2012; \& Ramirez et al., 2016). Each of the studies reported improvements for PSTs as a result of the intervention. There were three main categories of growth across these studies: (a) gained understanding of families, (b) increased confidence in working with families, and (c) a more positive attitude about the importance of working with families.

The most impacted area across these studies seemed to be PSTs' understanding of families and family life. The 
intervention in Bingham and Abernathy (2007) resulted in an improved understanding that teachers need to serve as advocates for children, but also that parents serve an important role in children's education as well. PSTs in two studies reflected a better understanding of the complexity of families' lives (Collier et al., 2015; Ramirez et al., 2017).

Along with improved understanding, PSTs reported improved attitudes or beliefs about families. PSTs gained an understanding of the importance of working with families (Brown et al., 2014). PSTs in Jacobbe et al. (2012) altered their beliefs about parents' motives and intentions regarding their children's education. Only one item (i.e., parents reinforce the importance of homework) was not changed from pre- to post-intervention. Ramirez et al. (2016) reported that PSTs significantly increased their belief that parents value education.

An important factor in whether teachers will implement a practice is whether they are confident in their ability to do so (Holdaway \& Owens, 2015). PSTs in several studies increased confidence in working with families. Collier et al. (2015) reported overall increase in confidence toward working with families. PSTs in Accardo and Xin (2017) increased their confidence in facilitating conferences and making decisions. McCollough and Ramirez (2012) found PSTs were significantly more confident engaging parents in children's education.

Only one study reported increases in the area of ability to implement practices for including families. PSTs in Bergman (2013) were able to list more strategies for welcoming parents and families. Notably, PSTs placed in urban settings listed significantly more strategies than PSTs placed in rural settings.

\section{Discussion}

The purpose of this literature review was to examine practices for preparing preservice teachers (PSTs) to collaborate with families. We specifically explored the introduction of family-centered practices because these practices could facilitate and promote parental involvement. The first research question that guided this review focuses on the strategies TPPs are employing to introduce PSTs to the concept of family-centered practices.

With one exception (Zeichner et al., 2016), all of the included studies implemented practices within a single course. Zeichner et al. incorporated activities within a 2-year initial licensing graduate program. Interventions varied by length, format, location of work/observation, person delivering the instruction to PSTs, type of assignment/activity, and whether or not PSTs came into contact with family members. A few studies ran the length of the semester, while others included a few events or activities within the semester. None of the studies featured only one day; even if the main event was a family-school night, there was preparation in days before and reflection in class periods after the event.

The activities used to introduce the concept of family-centered practices included lecture, article reading, class discussion and debriefing, group projects, research projects, simulation games, virtual reality simulation, field-based observation, panel discussions, lesson planning, attendance at extracurricular events, facilitating family-school learning events, interviewing and visiting with parents, neighborhood tours, and observing a poetry reading. Each study incorporated more than one of these activities. Work and observations occurred in various locations including university classroom, K-12 classrooms, school neighborhoods, and family homes. Most studies conducted activities in more than one location. Preparation for activities and debriefing discussions typically occurred in the university classroom, and experiences occurred in the university classrooms, K-12 classrooms, neighborhoods, and school neighborhoods.

The use of various teaching strategies and activities (e.g., reading, observing, and practicing) in various environments (e.g., schools and homes) are important for adult, such as PST, learning (Sandlin, Wright, \& Clark, 2011; Wang, Torrisi-Steele, \& Hansman, 2019) and with the opportunity to receive prompt feedback while in these authentic environments (Woods, Wilcox, Friedman, \& Murch, 2011). The effectiveness of professional development programs is significantly related to principles of adult learning (Green \& Ballard, 2011). Trivette, Dunst, Hamby, and O'Herin (2009) completed a meta-analysis of adult learning strategies associated with positive learner outcomes. They reviewed 79 studies and analyzed the presence of six characteristics of adult learning: (a) introduce, introducing new information/practice; (b) illustrate, demonstrating of the use of the information/practice; (c) practice, engaging the adult in the use of the information/practice; (d) evaluate, having the adult evaluate the outcomes; (e) reflection, having the adult reflect on the learning experience; and (f) mastery, engaging the adult in self-assessment of learned information/practice. Trivette and colleagues (2009) concluded that all six adult-learning characteristics are important and associated with positive adult outcomes.

In addition, the activities used to introduce the concept of family-centered practices were facilitated by university faculty, K-12 faculty, and families. PSTs were positioned as the observers and learners in all studies. University professors provided information and organized activities, family members shared information and experiences to help PSTs learn their perspectives, and K-12 faculty provided a space for PSTs to observe and practice their craft. One of the key elements of family-centered practice is engaging with family members to understand their lives, goals, strengths, and needs and developing relationships between families and professionals (DEC, 2014). Therefore, including family 
members in teacher preparation programs is an important component for facilitating PSTs learning.

Studies varied in whether and how directly PSTs interacted with families. Some studies did not provide direct interaction between PSTs and family members, but provided found poetry reading (McHatton et al., 2013), team projects with case study analysis (Accardo \& Xin, 2017), written exercises (Amatea et al., 2012), and PTE curriculum modules (Brown et al., 2014).

All other studies did allow for direct interaction between PSTs and families. In two studies, panel discussions or guest speakers included coordinators of local parent resource centers (Bergman, 2013), parents (Waddell, 2013; Zeichner et al., 2016), and school faculty (i.e., teachers \& school principals; Waddell, 2013). In six studies, PSTs interacted with families as they facilitated family-school nights (Able et al., 2014; Bofferding et al., 2016; Bottoms et al., 2017; Jacobbe et al., 2012; McCollough \& Ramirez, 2012; Ramirez et al., 2016). In these situations, students were able to observe parents and interact with them briefly. Amaro-Jimenez (2016) required 30 field experience hours which included attendance at family school events. Three studies allowed for PSTs' interaction with families in the home, engaging in conversations, and conducting service hours at parents' request (Able et al., 2014; Collier et al., 2015; Waddell, 2013). In two studies, PSTs conducted structured interviews with families or listened as families told their stories (Bingham \& Abernathy, 2007; Waddell, 2013). In two studies, family members served as faculty, co-facilitating university courses with university instructors (Collier et al., 2015; Murray et al., 2008). One of the six characteristics of adult learning is practicing whereby an adult engages in the use of the information/practice they learned (Trivette et al., 2009). Opportunities to interact with families and practice strategies for working with families is an important component in PSTs' learning.

The second research question that guided this review focuses on how TPPs' efforts impact PSTs' knowledge, practices, and attitudes toward and efficacy in implementing family-centered practices. The studies in this review focused almost exclusively on PST attitudes toward working with families. One exception, Bergman (2013), focused on increasing PST knowledge in a measurable way. No studies measured PST ability to implement family-centered practices. Two categories of outcomes emerged from this review of literature: (a) a new understanding of the importance and benefit of family-centered practices and (b) increased confidence for working with families.

\subsection{Understanding the Importance of Family-Centered Practices}

All studies reported changes in PSTs' perception of the importance and benefit of family-centered practices. Some studies reported this perception applied to general importance of working with families (Able et al., 2014; Amaro-Jimenez, 2016; Bergman, 2013; Bofferding et al., 2016; Bottoms et al., 2017; Ramirez et al., 2016; Waddell, 2013), and some listed perception changes about specific strategies or practices under the family-centered practices umbrella (Amatea et al., 2012; Bergman, 2013; Bingham \& Abernathy, 2007; Collier et al. 2015; McHatton et al., 2013; Murray et al., 2008; Ramirez et al., 2016; Zeichner et al., 2016).

PSTs in Collier et al. (2015) realized the importance of effective, two-way communication, relationship building, and positive language. In McHatton et al. (2013), PSTs learned the need for teachers to listen to families. The Early Childhood Technical Assistance Center (2018) created the family-centered practices checklist to help professionals to self-evaluate their use of family-centered practices. This checklist highlights the importance of communicating and building relationship with families, for example "work with family in collaborative manner to obtain family prioritized supports and resources" and "be responsive to the family's unique life circumstances" (http://ectacenter.org).

Similar to the need for improved communication, PSTs in Bingham and Abernathy (2007) perceived a need for teachers to play an advocacy role for students and families. Bingham and Abernathy reported a decreased perception of the importance of the teacher/school role in improving academic outcomes. It seems that the activities in that study highlighted the need to focus on family needs rather than making all decisions from a standpoint of academics, to the exclusion of family concerns. Family-centered practices "treat families with dignity and respect; are individualized, flexible, and responsive to each family's unique circumstances; provide family members complete and unbiased information to make informed decisions; and involve family members in acting on choices to strengthen child, parent, and family functioning" (DEC Recommended Practices, 2014, p. 10).

While reducing the importance of teacher, school, and academics, PSTs in some studies learned to consider families and their individual members as entities that participate in school and academics as part of a larger existence that includes family and societal life experiences outside of school. PSTs realized their own stereotypical thinking about families (Bottoms et al., 2017). PSTs in several studies gained a new understanding of families and the barriers they face (Bingham \& Abernathy, 2007; Collier et al., 2015; Murray et al., 2008) and a belief that parents do value education (Ramirez et al., 2016).

Along with changed perspectives about parents' attitudes toward schooling and the reduced importance of the teacher 
and school, PSTs altered their view of the parent role in education. Parents play the role of partner in education (Amatea et al., 2012; Murray et al., 2008). This viewpoint allows for parents to define involvement for themselves and to help shape their children's educational experiences. Finally, PSTs felt that parents and the diversity across families would be an asset rather than a deficit (Bottoms et al., 2017; Zeichner et al., 2016). Special education from early intervention through adulthood stresses the importance of finding strengths and talents and building on those to foster self-determination. Real experiences with families and reflection may have demonstrated these concepts to PSTs.

A rare exception to the positive reported outcomes came from McHatton et al. (2013) who reported negative perceptions of families after the intervention. PSTs felt that parents were withdrawn or did not seem interested in the academic activities or in their children's participation. As stated in the introduction, families can be reluctant and perceive educators and school staff as intimidating and unapproachable. Furthermore, it is not uncommon for parents to prefer a type of interaction or involvement that is not the specific type that the school staff suggest.

Several studies in this review showed that experience brings confidence; PSTs in Amaro-Jimenez (2016), Bofferding et al. (2016), Murray et al. (2008), and McCollough \& Ramirez (2012) gained confidence and a feeling of preparedness for working with families. PSTs in Accardo and Xin (2017) felt more prepared to facilitate parent-teacher conferences and to make educational decisions. Additionally, in Zeichner et al. (2016), a study of PSTs in a 2-year graduate program, PSTs reported they felt they could translate their knowledge into action.

\subsection{Limitations and Implications}

As with any review, there are a few limitations that need to be considered when interpreting the findings. First, this review is a scoping review and we didn't evaluate the rigor of the studies included. To conduct a systematic review, researchers need to use published quality indicators and standards (Council for Exceptional Children, 2014) to assess the quality of the studies included. Secondly, related to the process of identifying relevant studies, it is possible that we missed studies during our search and that using different key words would have resulted in different findings. For example, in addition to using parent and family we could have used caregiver. Furthermore, not all researchers are using the term family-centered practices and might use different terms such as family-capacity building and help-giving practices. Researchers might want to expand the key words and terms used to identify additional articles in future reviews.

There are also limitations to the studies included. It is not surprising that the majority of participants in the included studies were female and Caucasian; however, to have a better understanding of the range of perceptions and needs, more diverse group of participants should be sought. Additionally, the researchers used varied methodologies, methods, and tools and, therefore, it is difficult to compare and contrast among the different studies. One important finding of this review is that the studies focused almost exclusively on PSTs' attitudes toward working with families. One study assessed changes in knowledge, but none of the researchers evaluated implementation of family-centered practices by the PSTs. We know that shaping knowledge and attitudes is important, but these changes do not necessarily lead to shifts in practices. Therefore, it is important in future studies to evaluate changes in perception, attitudes, knowledge, and practices. Using observations (e.g., parent-teacher conferences and open houses) and permanent records (e.g., newsletters, e-mails, and notes to home) could help researchers identify the family-centered practices PSTs are using and their needed support.

\section{References}

Able, H., Ghulamani, H., Mallous, R., \& Glazier, J. (2014). Service learning: A promising strategy for connecting future teachers to the lives of diverse children and their families. Journal of Early Childhood Teacher Education, 35, 6-21. https://doi.org/10.1080/10901027.2013.874383

Accardo, A., \& Xin, J. (2017). Using technology-based simulations to promote teacher candidate parental collaboration and reflective instructional decision making. Journal of Technology and Teacher Education, 25(4), 475-494.

Allen, Q., \& White-Smith, K. (2018). "That's why I say, 'Stay in school": Black mothers' parental involvement, cultural wealth and exclusion in their son's schooling. Urban Education, 53(3), 409-435. https://doi.org/10.1177/0042085917714516

Amaro-Jimenez, C. (2016). Preservice teachers' reflections of their involvement in a home school connection project in teacher education. Bilingual Research Journal, 39(1), 69-85. https://doi.org/10.1080/15235882.2016.1139520

Amatea, E. S., Cholewa, B., \& Mixon, K. A. (2012). Influencing preservice teachers' attitudes about working with low-income and/or ethnic minority families. Urban Education, 47(4), 801-834. https://doi.org/10.1177/0042085912436846

Beauvais, C. (2017). An exploration of the 'pushy parent' label in educational discourse. Discourse: Studies in the 
Cultural Politics of Education, 38, 159-171. https://doi.org/10.1080/01596306.2015.1064098

Belway, S., Durán, M., \& Spielberg, L. (2010). State laws on family engagement in education. Retrieved from https://s3.amazonaws.com/rdcms-pta/files/production/public/State_Laws_Report.pdf

Bergman, D. J. (2013). Comparing the effects of suburban and urban field placements on teacher candidates' experiences and perceptions of family engagement in middle and high schools. School Community Journal, 25(2), $87-112$.

Bibby T., Lupton R., \& Raffo, C. (2017). Responding to poverty and disadvantage in schools. London, England: Palgrave Macmillan. https://doi.org/10.1057/978-1-137-52156-9

Bingham, A., \& Abernathy, T. V. (2007). Promoting family-centered teaching: Can one course make a difference? Issues in Teacher Education, 16(1), 37-60.

Bofferding, L., Hoffman, A., \& Kastberg, S. (2016). Family mathematics nights: An opportunity to improve preservice teachers' understanding of parents' roles and expectations. School Science and Mathematics, 116(1), 17-28. https://doi.org/10.1111/ssm.12109

Bottoms, S. I., Ciechanowski, K., Jones, K., de la Hoz, J., \& Fonseca, A. L. (2017). Leveraging the community context of family math and science nights to develop culturally responsive teaching practices. Teaching and Teacher Education, 61, 1-15. https://doi.org/10.1016/j.tate.2016.09.006

Brown, A. L., Harris, M., Jacobson, A., \& Trotti, J. (2014). Parent teacher education connection: Preparing preservice teachers for family engagement. The Teacher Educator, 49(2), 133-151. https://doi.org/10.1080/08878730.2014.887169

Bruder, M. B. (2010). Early childhood intervention: A promise to children and families for their future. Exceptional Children, 76(3), 339-355. https://doi.org/10.1177/001440291007600306

Calzada, E. J., Huang, K. Y., Hernandez, M., Soriano, E., Acra, C. F., Dawson-McClure, S., Kamboukos, D., \& Brotman, L. (2015). Family and teacher characteristics as predictors of parent involvement in education during early childhood among Afro-Caribbean and Latino immigrant families. Urban Education, 50(7), 870-896. https://doi.org/10.1177/0042085914534862

Cavendish, W. \& Connor, D. (2018). Toward authentic IEPs and transition plans: Student, parent, and teacher perspectives. Learning Disability Quarterly, 41, 32-43. https://doi.org/10.1177/0731948716684680

Collier, M., Keefe, E. B., \& Hirrel, L. A. (2015). Listening to parents' narratives: The value of authentic experiences with children with disabilities and their families. School Community Journal, 25(2), 221-242.

Council for Exceptional Children. (2014). Council for Exceptional Children standards for evidence-based practices in special education. Retrieved from:

http://www.cec.sped.org/ /media/Files/Standards/Evidence\%20based\%20Practices\%20and\%20Practice/CECs\%20 Evidence $\% 20$ Based $\% 20$ Practice $\% 20$ Standards.pdf

Council for the Accreditation of Educator Preparation. (2018). K-6 Elementary Teacher Preparation Standards. Retrieved from http://caepnet.org/accreditation/caep-accreditation/caep-k-6-elementary-teacher-standards

Curle, D., Jamieson, J., Poon, B. T., Buchanan, M., Norman, N., \& Zaidman-Zait, A. (2017). Working together: Communication between stakeholders during the transition from early intervention to school for children who are d/Deaf or hard of hearing. Exceptionality Education International, 27(2), 54-71. ISSN: 1918-5227

Curry, K. A., Gaëtane, J. M., \& Adams, C. M. (2016). Social networks and parent motivational beliefs: Evidence from an urban school district. Education Administration Quarterly, 52, 841-877. https://doi.org/10.1177/0013161X16659345

Division for Early Childhood (2014). DEC recommended practices in early intervention/early childhood special education 2014. Retrieved from http://www.dec-sped.org/recommendedpractices

Division for Early Childhood. (2014). DEC recommended practices in early intervention/early childhood special education 2014. Retrieved from http://www.dec-sped.org/recommendedpractices.

Dunst, C. J. (2002). Family-centered practices: Birth through high school. The Journal of Special Education, 36(3), 141-149. https://doi.org/10.1177/00224669020360030401

Dunst, C. J., Trivette, C. M., \& Hamby, D. W. (2007). Meta-analysis of family-centered helpgiving practices research. Mental Retardation \& Developmental Disabilities Research Reviews, 13, 370-378. https://doi.org/10.1002/mrdd.20176 
Found Poem. (n.d.). Poetic form. https://www.poets.org/poetsorg/text/found-poem-poetic-form. Accessed on April 7, 2019.

Green, G., \& Ballard, G. (2011). No Substitute for Experience: Transforming Teacher Preparation with Experiential and Adult Learning Practices. SRATE Journal, 20(1), 12-20.

Haley, K., Allsopp, D., \& Hoppey, D. (2018). When a parent of a student with a learning disability is also an educator in the same school district: A heuristic case study. Learning Disability Quarterly, 41(1). 19-31. https://doi.org/10.1177/0731948717690114

Holdaway, A. S., \& Owens, J. S. (2015). The effects of training and consultation condition on teachers' self-reported likelihood of adoption of a daily report card. Journal of Educational Psychology, 107(1), 222-235. https://doi.org/10.1037/a0037466

Individuals with Disabilities Education Act, 20 U.S.C. $§ 1400$ (2004).

Jacobbe, T., Ross, D. D., \& Hensberry, K. K. R. (2012). The effects of a family math night on preservice teachers' perceptions of parental involvement. Urban Education, 47(6), $1160-1182$. https://doi.org/10.1177/0042085912447805

Jeynes, W. H. (2017). A meta-analysis: The relationship between parental involvement and Latino student outcomes. Education and Urban Society, 49(1), 4-28. https://doi.org/10.1177/0013124516630596

Lechuga-Peña, S., \& Brisson, D. (2018). Barriers to school-based parent involvement while living in public housing: A mother's perspective. The Qualitative Report, 23(5), 1176-1187.

Li, A. \& Fischer, M. J. (2017). Advantaged/disadvantaged school neighborhoods, parental networks, and parental involvement at elementary schools. Sociology of Education, 90, 355-377. https://doi.org/10.1177/0038040717732332

McCullough, C., \& Ramirez, O. (2012). Cultivating culture: Preparing future teachers for diversity through family science learning events. School Science and Mathematics, 112(7), 443-451. https://doi.org/10.1111/j.1949-8594.2012.00158.x

McHatton, P. A., Bradshaw, W. L., \& Winneker, A. (2013). Introduction to working with diverse families through performance: Using ethnodrama as an instructional tool. Action in Teacher Education, 35, 38-55. https://doi.org/10.1080/01626620.2012.743444

Murray, M., Curran, E., \& Zellers, D. (2008). Building parent/professional partnerships: An innovative approach for teacher education. The Teacher Educator, 43, 87-108. https://doi.org/10.1080/08878730701838819

National Parent Teacher Association. (n.d.). Retrieved from www.pta.org

Parsons, A. A., Walsemann, K. M., Jones, S. J., Knopf, H., \& Blake, C. E. (2018). Parental involvement: Rhetoric of inclusion in an environment of exclusion. Journal of Contemporary Ethnography, 47, 113-139. https://doi.org/10.1177/0891241616676874

Pemberton, K. D., \& Miller, S. (2015). Building home-school relationships to enhance reading achievement for students with families with limited financial resources. Education and Urban Society, 47(7), 743-765. https://doi.org/10.1177/0013124513508979

Ramirez, O., McCollough, C. A., \& Diaz, Z. (2016). Creating a model of acceptance: Preservice teachers interact with non-English-speaking Latino parents using culturally relevant mathematics and science activities at family learning events. School Science and Mathematics, 116(1), 43-54. https://doi.org/10.1111/ssm.12150

Sandlin, J. A., Wright, R. R., \& Clark, C. (2011). Reexamining theories of adult learning and adult development through the lenses of public pedagogy. Adult Education Quarterly, 63, 3-23. https://doi.org/10.1177/0741713611415836

Stoddard, K., Braun, B., \& Koorland, M. (2011). Beyond the schoolhouse: Understanding families through preservice experiences in the community. Preventing School Failure, 55, 158-163. https://doi.org/10.1080/1045988X.2010.499394

The Early Childhood Technical Assistance Center. (2018). Family-centered practices checklist. Retrieved from http://ectacenter.org/ pdfs/decrp/FAM-1_Fam-Ctrd_Practices_2018.pdf

Thelamour, B., \& Jacobs, D. L. (2014). Homework practices of English and non-English speaking parents. Urban Education, 49(5), 528-542. https://doi.org/10.1177/0042085913481360

Valle, J. W. (2018). Across the conference table: Private and public mothering of children with learning disabilities. Learning Disabilities Quarterly, 41, 7-18. https://doi.org/10.1177/0731948717696258 
Waddell, J. H. (2013). Working with families in urban teacher education: A critical need for all students. The Teacher Educator, 48(4), 276-295. https://doi.org/10.1080/08878730.2013.826767

Wang, V. X., Torrisi-Steele, G., \& Hansman, C. A. (2019). Critical theory and transformative learning: Some insights. Journal of Adult and Continuing Education. https://doi.org/10.1177/1477971419850837

Woods, J. J., Wilcox, M. J., Friedman, M., \& Murch, T. (2011). Collaborative consultation in natural environments: Strategies to enhance family-centered supports and services. Language, Speech, and Hearing Services in Schools, 42, 379-392. https://doi.org/10.1044/0161-1461(2011/10-0016)

Zeichner, K., Bowman, M., Guillen, L., \& Napolitan, K. (2016). Engaging and working in solidarity with local communities in preparing the teachers of their children. Journal of Teacher Education, 67(4), 277-290. https://doi.org/10.1177/0022487116660623

\section{Copyrights}

Copyright for this article is retained by the author(s), with first publication rights granted to the journal.

This is an open-access article distributed under the terms and conditions of the Creative Commons Attribution license which permits unrestricted use, distribution, and reproduction in any medium, provided the original work is properly cited. 